\title{
Controlled Sequestration of DNA Intercalated Drug by Polymer-Surfactant Supramolecular Assemblies
}

Aruna K. Mora, Prabhat K. Singh, and Sukhendu Nath*

Radiation \& Photochemistry Division, Bhabha Atomic Research Centre, Trombay, Mumbai-400 085, India

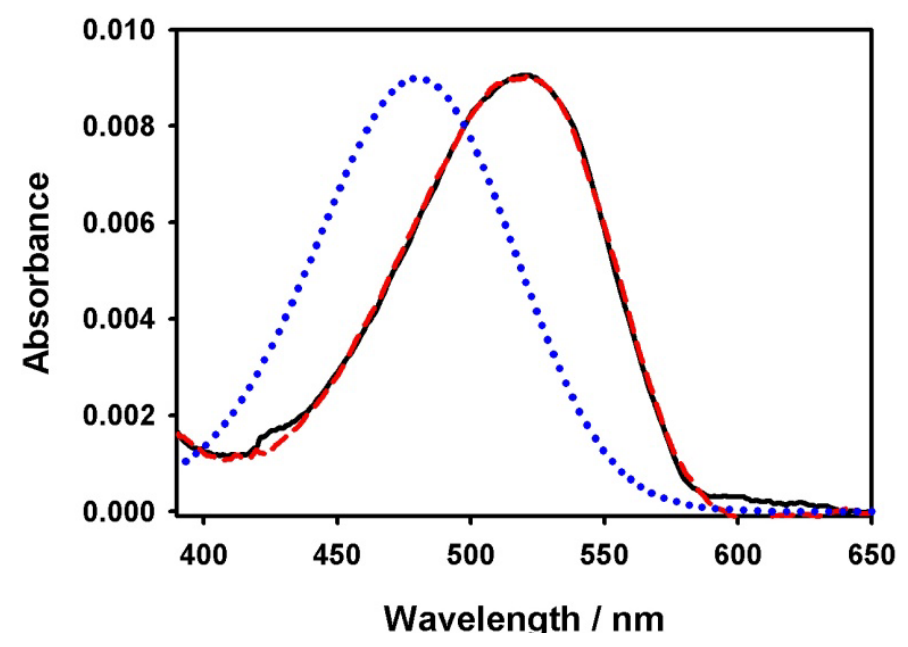

Figure S1: The absorption spectra of EB in (......) water, ( - ) DNA and $(----)$ DNAP123 solutions.

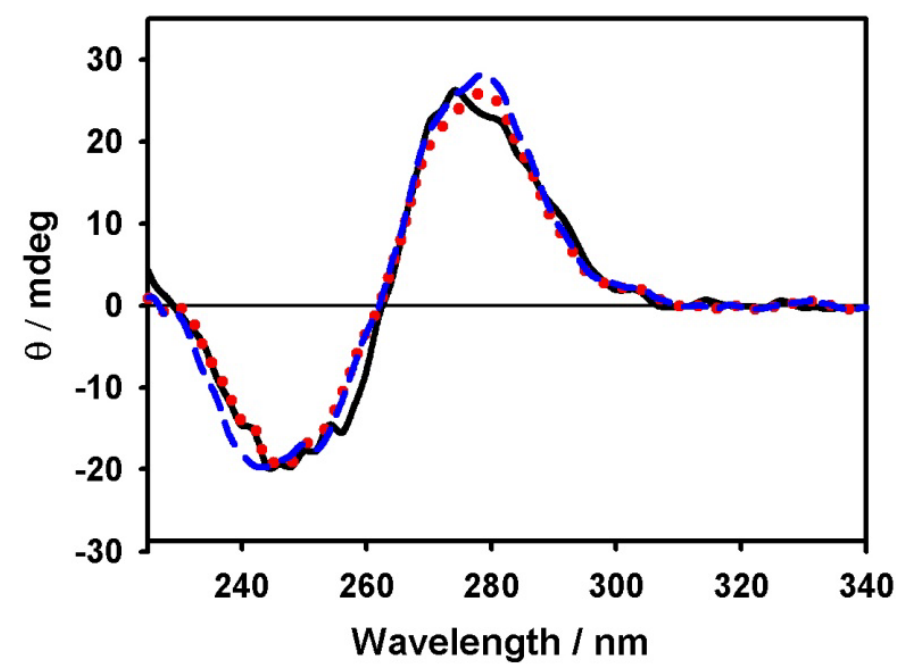

Figure S2:The circular dichroism (CD) spectra of DNA in (- $(-)$ aqueous solution, $(\ldots . . .$.$) in$ $10 \% \mathrm{P} 123$ solution and (---- $)$ in P123-SDS solution with $v=4$. 
Measurement of binding constant for $\mathrm{EB}$ with DNA: The binding constant for the association of EB with the DNA has been measured using steady-state emission measurements. The figure S3A shows the emission spectra of EB at different DNA concentrations. The binding constant for the association of EB with DNA has been measured by using the following equation. ${ }^{1}$

$$
\Delta \mathrm{F}=\left(1-\frac{[\mathrm{EB}]}{[\mathrm{EB}]_{0}}\right)\left(F^{\infty}-F^{0}\right)
$$

Where, $\Delta \mathrm{F}$ is the difference in the emission intensity of EB in the presence and absence of DNA. $[E B]$ and $[E B]_{0}$ are the concentration of the free EB in the presence and absence of DNA respectively. $F^{0}$ and $F^{\infty}$ are the intensities of $\mathrm{EB}$ at intermediate and at very high concentration of DNA when all the EB has been associated with DNA molecules respectively. The equilibrium concentration of $\mathrm{EB}$ at any concentration of DNA can be calculated by the following equation.

$$
[E B]=\frac{1}{2 \mathrm{~K}_{\mathrm{b}}}\left(\left(\mathrm{K}_{\mathrm{b}}[\mathrm{EB}]_{0}-\mathrm{K}_{\mathrm{b}}[\mathrm{DNA}]_{0}-1\right)+\sqrt{\left(\mathrm{K}_{\mathrm{b}}[\mathrm{EB}]_{0}+\mathrm{K}_{\mathrm{b}}[\mathrm{DNA}]_{0}+1\right)^{2}-4 \mathrm{~K}_{\mathrm{b}}^{2}[\mathrm{~EB}]_{0}[\mathrm{DNA}]_{0}}\right)
$$

Where, $[\mathrm{EB}]_{0}$ and $[\mathrm{DNA}]_{0}$ are the total concentration of EB and DNA and $\mathrm{K}_{\mathrm{b}}$ is the binding constant. The variation of $\Delta \mathrm{F}$ with the concentration of DNA are shown in figure $\mathrm{S} 3 \mathrm{~B}$. The experimental data were fitted with the eq. S1 and the binding constant thus estimated is $1.12 \times 10^{5}$ $\mathrm{M}^{-1}$. 

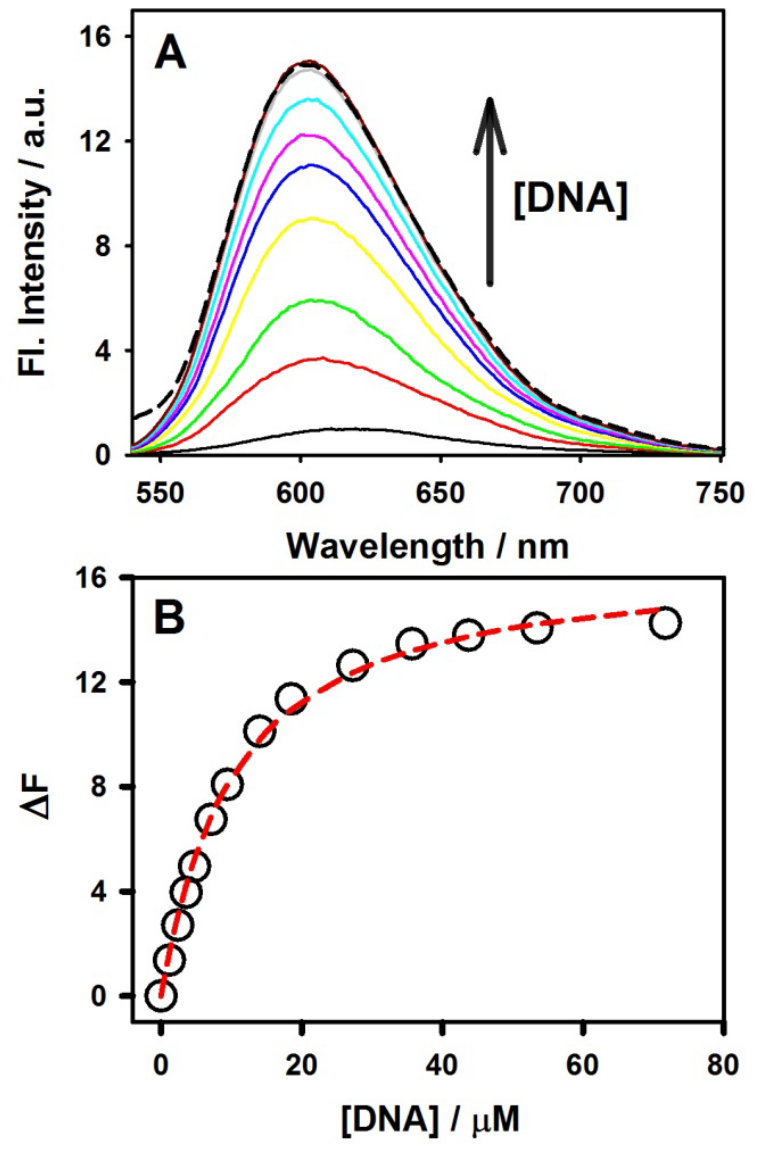

Figure S3: (A) The changes in the emission spectra of EB in the presence of different concentrations of CTDNA. The dashed curve is the emission spectrum of EB in DNA-P123 solution. (B) Variation in the emission intensity of EB with DNA concentration. The dashed line is the fitting of the experimental points by eq. $\mathrm{S} 1$. 

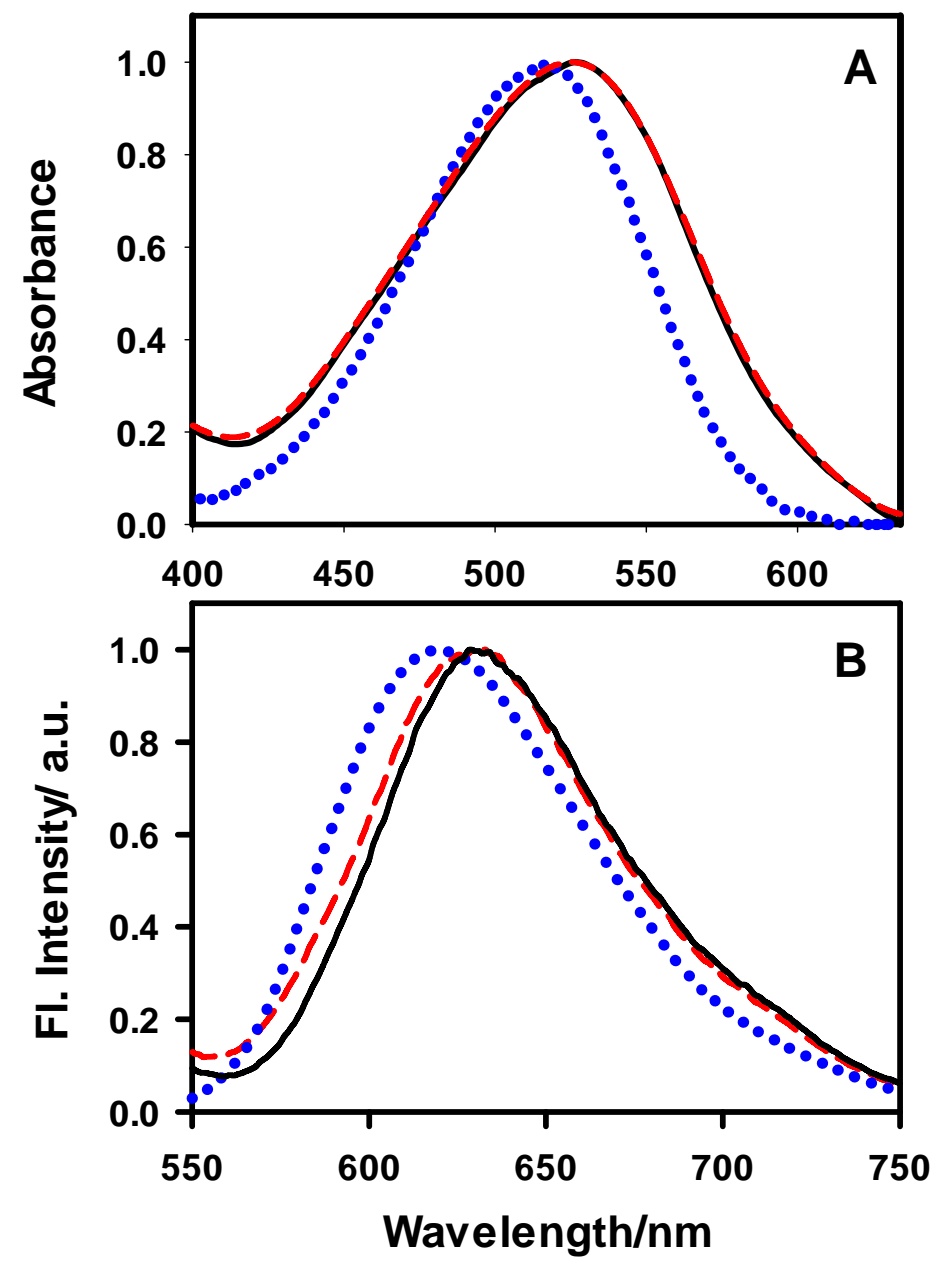

Figure S4: (A) Ground state absorption spectra and (B) steady-state emission spectra of EB in DNA-P123-SDS (- - - ), P123-SDS (— ) and SDS (…...) solutions. The concentration of SDS in all solutions are same and corresponds to $v=4$. 
Table S1: Global fitting parameters for the emission transient decays for EB in CTDNA-P123SDS solutions of different $v$ values

\begin{tabular}{|l|l|l|}
\hline \multicolumn{1}{|c|}{$v$} & \multicolumn{1}{|c|}{$\mathrm{A}_{1}{ }^{\alpha}$} & \multicolumn{1}{|c|}{$\left(\mathrm{A}_{2}+\mathrm{A}_{3}\right)^{\beta}$} \\
\hline 0.00 & 100.0 & 0.0 \\
\hline 0.12 & 94.5 & 5.5 \\
\hline 0.25 & 85.4 & 14.6 \\
\hline 0.38 & 75.1 & 24.9 \\
\hline 0.50 & 57.8 & 42.2 \\
\hline 0.75 & 46.9 & 53.1 \\
\hline 1.00 & 37.5 & 62.5 \\
\hline 1.25 & 24.7 & 75.3 \\
\hline 1.50 & 20.2 & 79.8 \\
\hline 2.00 & 16.8 & 83.2 \\
\hline 2.50 & 16.0 & 84.0 \\
\hline 3.00 & 11.7 & 88.3 \\
\hline 3.50 & 9.6 & 90.4 \\
\hline 4.00 & 3.9 & 96.1 \\
\hline
\end{tabular}

$\alpha$ - amplitude for the 21.2 ns decay component corresponding to the EB associated with DNA. $\beta$ - combined amplitudes for the $0.85 \& 4.3$ ns decay components corresponding to the EB associated with P123-SDS supramolecular assemblies.

Table S2: Global fitting parameter for the emission transient decays for EB in CTDNA at different SDS concentrations.

\begin{tabular}{|l|l|l|}
\hline$[\mathrm{SDS}] \times 10^{3} \mathrm{M}$ & $\mathrm{A}_{1}{ }^{\alpha}$ & $\left(\mathrm{A}_{2}\right)^{\beta}$ \\
\hline 0.0 & 100 & 0 \\
\hline 1.3 & 94.8 & 5.2 \\
\hline 2.6 & 95.0 & 5.0 \\
\hline 4.4 & 91.4 & 8.6 \\
\hline 5.6 & 85.4 & 14.6 \\
\hline 7.3 & 31.3 & 68.7 \\
\hline 8.4 & 9.3 & 90.7 \\
\hline 9.4 & 4.1 & 95.9 \\
\hline 11.8 & 2.0 & 98.0 \\
\hline 16.1 & 1.1 & 98.9 \\
\hline 68.0 & 0.6 & 99.4 \\
\hline
\end{tabular}

$\alpha$ - amplitude for the 21.3 ns decay component corresponding to the EB associated with DNA $\beta$ - amplitude for the $4.63 \mathrm{~ns}$ decay component corresponding to the EB associated with SDS micelles. 


\section{Reference:}

1. Singh, M. K.; Pal, H.; Koti, A. S. R.; Sapre, A. V., Photophysical properties and rotational relaxation dynamics of neutral red bound to $\beta$-cyclodextrin. J. Phys. Chem. A 2004, 108, 1465-1474. 